\title{
The Composition and Case Study of the Nurses' Voluntary Turnover Cost in China
}

\author{
Min Li \\ School of Business, Henan University, Kaifeng, China \\ Email:1mncee@163.com
}

How to cite this paper: Li, M. (2017) The Composition and Case Study of the Nurses' Voluntary Turnover Cost in China. Modern Economy, 8, 834-846.

https://doi.org/10.4236/me.2017.86058

Received: April 24, 2017

Accepted: June 19, 2017

Published: June 22, 2017

Copyright $\odot 2017$ by author and Scientific Research Publishing Inc. This work is licensed under the Creative Commons Attribution International License (CC BY 4.0).

http://creativecommons.org/licenses/by/4.0/

\begin{abstract}
Nurse is the largest number of four medical personnel, and the stability of the nurses is directly related to the quality of medical service, but countries around the world are faced with the high turnover rate of nurses [1]. At present, Chinese researches on the issue of nurses' resignation mainly focus on the analysis of the variables and causes of nurses' resignation, while there is few research related to the turnover costs of nurses which the managers focus most. All these problems lead to there is still no consensus and cognition on composition and measurement methods of turnover costs and the harm of the organizations. Based on the literature research, this paper summarizes the composition and measurement of the voluntary turnover cost of Chinese nurses, and draws the main constituent elements and feasible measurement methods of the nurses' voluntary turnover cost. Furthermore, this paper takes a military hospital in Beijing as an example and shows the composition and measurement methods of turnover cost by the actual measurement of the nurses' turnover costs in this hospital. Hope this paper can provide some reference for the future theoretical research and medical practice.
\end{abstract}

\section{Keywords}

Nurses, Voluntary Resignation, Explicit Cost, Hidden Cost, Turnover Cost

\section{Introduction}

Nurse is the largest number of four medical staff in the medical field (medical and epidemic staff, pharmacy staff, nurses and other technical staff), and play an important role in the medical service process. "Three treat, seven raise" is cognition in the medical field, but the tendency of preferring doctors to nurses in our society is very obvious. The low status, poor treatment, high workload and pressure lead directly to the phenomenon of the turnover of nurse increasing rapidly in recent years. The high proportion of voluntary turnover of nurses will inevit- 
ably have a negative impact on the quality of medical services provided by medical institution, the organizational performance of medical institutions, the development of public hospitals, and the reform of the entire health care system [2]. In view of this, the CPC Central Committee and State Council made a new medical reform clearly pointing out: we have to strengthen the construction of nurses, and gradually solve the problem of low proportion of nurses in March 2009. Ministry of Health's "quality care services demonstration project" in 2010 also clearly stated that something should be done to improve the human resources management of nurses and enrich the clinical nurses.

The problem of nurses' voluntary turnover also arouses medical management researchers' attention, which can be proved by related researches both at home and abroad. However, the current study on the nurses voluntary turnover focuses on the relationship between the reasons for the resignation of nurses and the relationship between the intention of turnover and other variables, while there is few research related to the turnover costs of nurses which the managers focus most [3]. Now, there are two questions that need to be solved: first, the definition of turnover costs is ambiguous and subjective; second, the measurement methods of the turnover costs are excursive [4].

\section{The Analysis of the Composition of Nurses' Turnover Costs in China}

The study of voluntary turnover costs measurement is not lacking, but it is always unable to form a consensus. Based on the analysis of existing employee turnover costs, the current research is mainly focused on three categories.

\subsection{Put the Turnover Cost in Human Resource Costs}

One of the human resource cost studies is the cost of turnover of human resources. However, there are three kinds of understanding of the turnover cost: the first one is the three-factor theory that the staff turnover costs including: the separation costs (due to the organization dismissed employees to pay the wages and compensation), the cost of ineffective work before leaving (the cost of inefficiencies between staff is ready to leave but not leave), the vacancy cost (the cost of loss resulting from the replacement of qualified staff at the time of employee turnover) [5]. The second method is the four-factor theory which contains: preemployment compensation costs, turnover management fees, pre-employment costs and the vacancy cost. Compared with three-factor theory, four-factor theory also takes the turnover management fees (when employees need to leave from the staff to handle various procedures) into consideration. The third method is the five-factor theory: severance compensation, liquidated damages (employees received by the employee due to breach of labor contract or agreement to resign to pay the enterprise to the cash income or other forms of economic benefits), the dismissal costs, the inefficient cost before leaving and the vacancy cost. The five-factor model adds an important item to the employee's liquidated damages, which is a reduction in the cost of organizing human resources. In fact, 
this is also a powerful tool for enterprises to be able to restrict employees to leave their jobs voluntarily [6]. However, there is little provision for liquidated damages, and few hospitals have specially trained the nurse when a labor contract is signed between a public hospital and a nurse. Therefore, breach of contract in the voluntary turnover costs is almost non-existent in practice.

Because this kind of research takes the turnover costs as the part of human resource costs, but human resource costs include human resource acquisition costs, human resource development costs, human resource use costs and human resource separation costs. So this classification method doesn't clearly take the recruitment and training costs into consideration, which is the most unreasonable place.

\subsection{Factor Analysis of the Turnover Costs}

This classification method is taking all the costs caused by staff turnover into consideration. It also goes through the three-factor, four-factor, and five-factor theory. The learner initially thought that the employee turnover costs consisted of three factors: separation costs (due to the cost of employee turnover required, such as severance pay, dismissal costs, turnover management costs, etc.), replacement costs (the cost of the recruitment process required for the recruitment of qualified new employees) and the training costs (the costs of necessary training for new employees to carry out the necessary management and professional trainings [7]). After 1982, on the basis of the above three types of cost factors, Wayne Cascio added a new cost, which was the cost of differences between new and old employees caused by the cost of loss. That is also called learning curve loss [8]. All these formed the four-factor method. After this, the scholars had added a new cost, namely vacancy costs. It refers to companies do not find qualified employees to replace the loss after the staff leaving the job. Thus, the composition of employee turnover costs are divided into five factors: separation costs, vacancy costs, replacement costs, learning curve losses, training costs (Fitz-Enz, 1997 [9]; Pinkovitz, Moskal \& Green, 1997 [10]).

The advantage of the classification is that it takes all factors caused by the stuff turnover which makes a negative effect on organization into consideration. It can clearly reflect the cost loss of the organization's voluntary turnover to the organization, and the boundaries are clear and easy to understand. It shows there is a certain relationship between training and turnover. Training costs are also part of the turnover costs [11]. But its shortcomings are also obviously, it is only considered the certain cost of the staff turnover and ignores the uncertainty of the potential cost. So the impact of the cost caused by stuff turnover is not fully demonstrated.

In addition, some cost items can be calculated directly, and some cost items cannot be directly calculated. The estimate is also very difficult.

\subsection{Classification of the Turnover Costs Factors}

In order to make up the shortcomings of the second category of research and 
clear the nature of the various separation costs, some scholars classified the separation costs. There are three categories of the current classification, one is divided it into tangible costs and intangible costs. But different scholars have disagreements with the content two categories included. Some scholars believe that tangible costs include separation costs, vacancy costs, replacement costs and training costs, and intangible costs include loss of knowledge and skills, productivity decline, organizational efficiency decline, customer loss, increased competitors, brand reputation decline, product quality decline, loss of business opportunities [12]. Other scholars believe that tangible costs include acquisition costs, training and development costs, while intangible costs include vacancy costs, psychological impact, efficiency cost, and so on. Second, the turnover costs are divided into pre-employment costs and post-employment costs. Pre-employment costs include advertising and recruitment expense, vacancy costs and employment expense. The costs of post-employment mainly include the cost of helping the staff qualify the job and training, learning curve loss, the loss of the pre-employment rate decline and the cost of terminating the contract [13]. Third, the turnover costs are divided into direct costs and indirect costs. The author held this point of view before and thought that the direct costs include replacement costs and training costs. Indirect costs include vacant costs, human capital investment costs, learning curve loss and efficiency costs.

But after discussion with the accounting scholars, I found that the classification of the direct cost and indirect cost is not accurate enough. The difference between the direct and indirect costs of accounting is whether it can be directly included in the cost object. What can be directly recognized is direct cost, while what can be allocated into rather than directly recognized is indirect cost. Such as the productions between $\mathrm{A}$ and $\mathrm{B}$, consuming three materials, A material can only be used for A products. B material can only be used for B products. C materials can be both used for $A$ products and B products at the same time, which cannot be directly distinguished the usage amount of $\mathrm{A}$ and $\mathrm{B}$.Then material $\mathrm{A}$ and $\mathrm{B}$ are the direct costs. Material $\mathrm{C}$ is an indirect cost. Take example by the concept of cost in management accounting, we can use explicit costs and hidden costs to distinguish it. Explicit costs can be understood as directly related to turnover behavior and accompanied by the cost of direct economic benefits outflow, In general, this amount is relatively fixed; hidden costs refer to related to the turnover behavior but not directly lead to economic benefits outflow. In general, this amount is uncertain. Obviously, the concept of the turnover costs with explicit and hidden costs should be more appropriate.

It can learn from the previous studies that the turnover costs include the replacement costs, the training costs, the separation costs, the vacancy costs, the human capital investment costs, the learning curve loss and the efficiency costs. Replacement costs include advertising cost, recruitment cost, the testing cost, the cost of going through the procedures and so on. Training costs include theoretical training and practical operation of the training costs of new and old staff and items etc. Departure management fees include the cost of labor and goods for 
handling various procedures. The several pay includes the dismissal of employees' severance galaxy, compensation and settlement fees due to the organization's dismissal. Vacancy costs include the increase cost of overtime work for in-service nurses caused by demission, the loss of delaying for patient or medical services and the decline of medical service quality and the human capital investment beyond retrieve. The cost of learning curve loss includes the time, medical material or financial loss caused by different performance in poor quality of the receiving and curing or the poor quality of the medical service between the old and new nurses. The efficiency cost includes the cost of inefficient of nurses before leaving, the cost of excellent technology and experience loss, and the frequent loss of excellent nurses bringing morale damage to other nurses and the loss of the efficiency of organizational cohesion.

According to the concept of explicit costs and hidden costs, we can see that explicit costs include replacement costs, training cost, the turnover management costs, and the cost of severance pay. The vacancy costs, the human capital investment costs, the learning curve loss costs, efficiency costs are the hidden costs. It is important to note that is the composition of the turnover costs, rather than the composition of the voluntary turnover costs. Combined with the characteristics of the nurses industry and the previous study, the severance compensation in the case the voluntary turnover is zero. If the medical institutions and nurses signed a labor contract with terms about labor constraints and cleared compensation measures, we need to pay to the medical institutions when nurses leave the work. Now, the voluntary explicit costs of nurses are replacement costs + training costs + turnover costs. The hidden costs are vacancy costs + learning curve loss costs + human capital investment costs + efficiency costs.

From the above we can know that nurses voluntary turnover costs are divided into two categories: explicit costs and hidden costs. Explicit costs include: replacement costs + training costs + turnover management fees. Hidden costs are the sum of vacancy costs, human capital investment costs, learning curve loss costs and efficiency costs.

\section{The Measurement Methods of the Nurses' Turnover Costs}

Knowing the contents of the turnover costs are only the basis of cost calculation, and the more important issue is the calculation of the voluntary turnover costs of nurses. The measurement methods of the human resource costs are the historical cost method, the reset cost method and the opportunity cost method. The historical cost method is a measuring method by the actual expenditure. It reflects the original investment of the enterprise to human resources. It is verifiable. The reset cost method is the expenditure which is to obtain the existing human resources in the current market conditions by the enterprise. It puts the human resources expenditure of the past time to the current economic conditions and reflects the current value of the enterprise human resources and all the investment. The opportunity cost method is abandoning the highest yield in other uses due to the use of human resources for a particular purpose. In these 
three measurement methods, the reset cost method and the opportunity cost methods have the subjective estimation component and they cannot accord with the traditional accounting pattern. Therefore it is also very difficult for people to accept. So the historical cost method is the main method used in the human resources costs.

Many medical organizations hope that the human resources department can calculate the specific value of the nurses' turnover costs. But there is little of the real calculation of the study because of the complexity and practicality of hospital management. Human resource management scholars have made some explorations of the voluntary turnover costs of the nurses using by the historical cost method. Although some are superficial, they can already reflect the serious cost loss caused by the current voluntary turnover of nurses. There are three main types of research.

\subsection{Practice Investigation Method}

We take the study conducted by Cheryl Bland Jones for NTCCM (Nursing Turnover Cost Calculation Methodology) as a representation. This study was a longitudinal series of studies, spanning 15 years. The first study was in 1990, and the second revised study was in 2004. The first study was conducted in four acute care hospitals. Researchers collected data through the semi-structured questionnaires, dividing the turnover costs into direct costs and indirect costs. The direct costs include employment costs, recruitment, advertising costs and vacancy costs. Indirect costs include positioning and training costs, termination of contract costs, and learning curve loss costs. They got the data of each part through the survey and summed up, then they have the conclusion that the turnover costs for nurses is about $11 \%$ of annual salary, which is slightly higher than the monthly salary [14]. The study is a typical historical cost method, summing up the historical data through the empirical research. However, from the previous study we can see that it only considered the explicit cost ignoring the hidden costs. It failed to fully reflect the true loss cost caused by nurses' turnover. But as an early study of the nurses' turnover costs, it still has the significance which cannot be ignored.

Because some cost factors were not considered and some survey data were not accurate enough in the first study, the researchers further revised the study in 2004. The second study was conducted at an acute care hospital. The method was still using a semi-structured questionnaire to collect data.

The second study has three major progresses compared the first study: firstly, regarding the nurses as the "knowledge workers" increase this part of the turnover costs through the human capital theory. Secondly, it changes the way to divide the turnover costs from the direct costs and indirect costs into the pre-employment costs and post-employment costs. Taking the behavior-hiring as a node, pre-employment costs and direct costs is same in the category while a slight difference in specific content. Post-employment costs add a new content compared to indirect costs. It is the changes of individuals and groups produc- 
tivity before 3 months the nurses leaving. Thirdly, the researchers redefine and refine the cost categories and cost elements of the first study and redefine their calculation methods. They organized the expert group involving the nursing researchers, economists, financial experts and nursing managers. The group evaluated new cost categories, cost elements and calculation methods.

The second study showed that the maximum proportion of voluntary turnover costs of nurses is vacancy costs, which is about $75 \%$ of the total turnover costs; and positioning costs $(<10 \%)$ and training costs $(<10 \%)$, replacement costs $(<5 \%)$, termination contracts meaning the cost of leaving management $(<1 \%)$ are the smaller proportion of the cost of leaving the nurses.

In view of the previous study, the explicit costs of nurses' are replacement costs + training costs + turnover management costs according to Cheryl Bland Jones's real data practice survey. We can see this part is about $15 \%$. Hidden costs (vacancy costs + human capital investment costs + learning curve loss costs + efficiency costs) are about $85 \%$.

\subsection{Numerical Prediction Method}

Practical survey analysis is relatively accurate but its workload can be very large if it is necessary to understand the nurses' turnover costs every year. Carrying out a large-scale practice investigation is clearly unrealistic. So Cheryl Bland Jones can estimate the turnover costs on the basis of the practice of investigation by considering the adjustment factor. Although it is not very accurate, the workload is relatively small and it is practical powerfully. With the deepening of knowledge, the researchers have adopted three adjustment indicators: consumer price index, inflation and regional size index.

The first study conducted in 1992 was the adjustment of the consumer price index (CPI) for the data obtained from the 1990 practice survey. Researchers analyzed the changes in the CPI index from the 1988 CPI to the 1991 CPI to estimate the nurses' turnover costs in 1992 [15].

The second study was conducted in 2008 to analyze the data obtained from the 2004 practice survey with inflation rate and regional size index. The complexity of this study is that it does not just consider a single total inflation rate. They divide inflation rates into three categories: the overall inflation rate, using the country inflation rate; the second is the hospital service inflation rate (hospital service index). It was first published in 1997. It reflects the labor price index and the inflation rate is higher; the third is the professional services (psychiatric services, dental services, ophthalmic services, other medical services). It is mainly used to estimate the labor cost which can be obtained by querying the National Registered Nurse Sample Survey. Different types of nurse turnover costs need to be adjusted with different rates of inflation. At the same time, the study also takes into account that the adjustment coefficient of different regions should be different. For example, the adjustment coefficients of the southern city and the northern city are different and the adjustment coefficients of large cities and small cities are different, so using the regional size index which is published by 
the government is suitable [16]. The transformation of the study can be summarized as

$$
\mathrm{CY}=\Sigma \mathrm{CiX}+\{[(\text { CPIiy } * \text { Cix })-\text { Cix }] * \operatorname{Igy}\}
$$

Note: CY: the cost in $\mathrm{Y}$ year

Cix: the $\mathrm{i}$ cost in $\mathrm{X}$ year, $\mathrm{i}=1,2$, 3. (1: advertising, hiring and termination contract costs; 2 : vacant costs, training and productivity reduction costs; 3 : the patient staying delay and other costs)

CPI iy: the i kind of CPI data in Y year

Igy: regional/city size adjustment index in $\mathrm{Y}$ year

\subsection{Model Calculation Method}

There are few studies about the model quantitative research of nurses' turnover costs. There are three studies to carry out the work by using for reference to model quantitative research of employees turnover costs.

One is Cascio's employee turnover cost model. The model which is detrimental to the employee's turnover costs will be divided into four categories: termination costs, replacement costs, training costs and learning curve loss costs. By summing up these four types of cost models, the employee turnover cost model is obtained. Zhang Yancai amended the model on the foundation of the Cascio model in 2007. One is that divided the turnover costs into direct costs, indirect costs and the financial value loss of the morale impacting. Second, increase the new turnover costs multiplier. Because the time of the new employees entering the business is relatively short and the possibility of leaving is large, it is appropriate to enlarge the cost. That is, the total employee turnover costs should be enlarged properly. Basing on these two considerations, the study considers the total turnover costs:

$$
L=(D+I)(1+f)
$$

$D$ : direct cost, $I$ : indirect cost, $f$ new employee turnover cost multiplier. By assigning these factors, you can get the total turnover costs.

The second study was the use of AHP (Analytic Hierarchy Process) for human resource cost studies. It is generally a decision in three layers. The first layer is the target layer. It has only one factor. The second layer is the criteria layer. It can have multiple factors. The third layer is the program layer. It also has multiple factors. And it compares the same level of factors according to the two comparison matrix, then getting the weight through a standard and finally making the total ranking and consistency of the test. It regarded the turnover costs as the target layer, the explicit costs and hidden costs as the criterion layer. We can regard the replacement costs, the vacancy costs, the human capital investment costs, the learning curve loss costs, and the efficiency costs as the third program layer. And then we get the matrix of the relative importance of each element in each layer through the expert group. At last, we can calculate the output of the index weight of each level by using the yaahp0.5.2 software and have the consistency test. When the ratio is less than 0.1 , the consistency ratio is passed. Then 
you can derive the weight of each feature to the target layer. When we can get the each cost, we can calculate the total costs [17].

The third study is the calculating method of the voluntary turnover costs of nurses. Xiong Yongqing had split costs into tangible and intangible costs. The tangible cost is calculated by historical cost method, and the intangible cost is calculated by estimating which is more feasible [12]. Tangible costs include separation costs, vacancy costs, replacement costs and training costs. Because the researcher defines the vacancy cost $=$ overtime pay + temporary employee's salary-the wage saved, this amount is relatively small. The tangible costs mainly have the replacement costs, the training costs and the separation costs. Intangible costs calculate mainly by using the evaluation method. Firstly, determine the set of elements of intangible costs, such as $U=$ [loss of knowledge and skills, productivity decline, organizational efficiency decline, etc.], Elements Level V = [very important, important, slightly important, ordinary, unimportant]. According to the expert group's study, determine the weight of the various elements, such as $\mathrm{A}=(0.1,0.05,0.04$, etc.). Through the matrix normalized processing and the experts' discuss, ultimately we can find that the intangible costs account for $80 \%$ of the total costs. Tangible costs can be calculated. The total costs are the sum of intangible costs and tangible costs. Then we can derive the total cost.

Throughout the three types of methods, the practice investigation method and the quantitative calculation method have obtained similar conclusions. Although the definition of the name is different, the sum of replacement cost, training costs, management costs account for $15 \%$ to $20 \%$ of the total costs. The others costs such as vacancy costs, learning curve loss costs, human capital investment costs, efficiency costs account for $80 \%$ to $85 \%$ of the total cost. The replacement costs, training costs, management costs are the explicit costs which can be tentatively set at $15 \%$ to $20 \%$. While the hidden costs account for $80 \%$ to $85 \%$ of the total costs of voluntary turnover. The hidden costs are four to five times the explicit costs.

At the same time, combining with the existing research and the actual situation of Chinese medical institutions, we suggest the managers can analyze the turnover costs by the method of this study when managers do not have the time and energy to carry out a large number of data collection calculation. The explicit costs can be accurately investigated and calculated. Then the hospital managers combined with empirical data to estimate the hidden costs. At last, they estimate the new employee turnover cost multiplier to adjust. They can get a relatively accurate nurses turnover costs data, Total Turnover Cost:

$$
L=(D+I)(1+f)
$$

$D$ : direct costs, $I$ : indirect costs, $f$ new employee turnover cost multiplier.

\section{The Empirical Analysis of the Nurses' Voluntary Turnover Costs}

A military hospital is a grade A tertiary hospital which has the set of medical, 
health care, teaching, research, rescue. It is large, modern and comprehensive. It was officially opened in 1990, currently which has 1300 beds and more than 70 professional departments. It has more than 400 experts who are from different majors, among them more than 100 experts receiving special allowance of the State Council and the military talents post allowance. The hospital has a lot of domestic first-class modern medical equipment. The total value is more than 600 million yuan. It is a national "post-doctoral research station", "China International Rescue Medical Base", the famous medical and teaching base.

The hospital currently has 712 nurses. There were 168 nurses leaving and 148 new recruiting nurses from January of 2012 to May of 2013. After the wage system reforming, the hospital wages system is slant to the health care personnel. The nurses' wages are from three parts: basic salary, bonuses, and night shift wages. The average of their wages is about 4800 yuan. The average salary of hospital managers is 4500 yuan. Handling the resignation need spend about 2 hours; recruitment advertisements showed in the hospital website do not have advertising costs. It takes nurses about 5 hours to candidate, collect material, interview and apply for this job. New nurse training by the hospital needs a week to carry out, including classroom teaching for 3 days and practice for 4 days. Classroom lectures require nursing specialists to teach all day, practice needs the main training in various departments. There is no liquidated damages clause when signing the labor contract.

The explicit cost is: replacement costs, training costs and turnover management fees. Replacement costs include: advertising costs, recruitment costs, the cost of entry testing, the entry cost and so on. Training costs include: theoretical training costs and the actual operation costs. The turnover management fees are the labor and goods costs of handling various procedures. The average salary of managers is 4500 yuan, the hourly wage is about 25 yuan. Advertising cost is 0 . Recruitment costs are about $25 \times 5=125$ yuan, material costs are about 5 yuan. Per capita recruitment fee is 130 yuan. The average wage of nurses monthly is 4800 yuan, the daily wage is about 230 yuan. Generally there are 20 nurses having classroom training together about the per capita classroom teaching. The cost for teachers is: $3 \times 230 / 20=35$. With practical training for one-on-one training, training time is about 4 hours a day. The cost of per capita practice for teachers is: $230 \times 2=460$. New nurse 7 daytime costs: $230 \times 7=1610$. Material costs are negligible. The per capita training cost is: $35+460+1610=2105$. The departure fee is about 2 hours. Because of the mainly online processing, material costs can be ignored. Turnover management cost: $25 \times 2=50$. The explicit costs were: $168 \times 50+148 \times(130+2105)=339,180$ from January of 2012 to May of 2013. From the results we can see the voluntary explicit costs of nurses are about 0.34 million.

After that the researchers and hospital experts conducted in-depth interviews, we take two ways to analyze the total cost of the nurses' voluntary turnover. One is the direct estimate method. After communicating with the director of the hospital, the hospital leader, the human resources department leader and the vice 
president, the experts discussed that the explicit cost was about $20 \%$ of the total costs and the hidden cost was about $80 \%$. The second method is the model estimation method. Firstly, determine the set of hidden costs, such as $U=$ [vacancy costs, learning curve loss costs, human capital investment costs, efficiency costs], Element Level V = [very important, important, slightly important, ordinary, unimportant]. The weight of the value elements, such as $\mathrm{A}=(0.2,0.1,0.4,0.3)$, which is determined by the expert group. Through the matrix normalization process and experts' discuss, and then ultimately they set that hidden costs accounted for $82 \%$ of the total cost. The explicit costs have been calculated about 0.34 million yuan. Total Turnover Costs

$$
L=(D+I)(1+f)
$$

$D$ : explicit costs, I: hidden costs, f: new employee turnover cost multiplier. After the panel discussion, the new employee turnover cost multiplier was set at $5 \%$. The total cost is $L=(0.34+1.36) \times 1.05=1.785$ million yuan by the direct estimate. The total cost is $L=(0.34+1.55) \times 1.05=1.985$ million yuan by the model estimate. There is a slight gap between the two method outcomes, but on the whole they both generally reflect the reality of the high nurses' turnover costs.

There is a noteworthy phenomenon here. At the time of the initial interview, HR managers continued to stress that the nurses had very little turnover costs and had only two hours to complete. In the interview of being asked the new staff recruitment and training costs, they insist that there is no cost. The recruitment is on the site, including interviews and procedures for each person which does not exceed 5 hours. Training teachers are their senior nurses. New nurses only need to spend a week to lean. It seems that the cost is very low. But the real cost of the calculation has been made some people surprised. The total turnover costs of nurses are about 2 million yuan for a year. Because of the huge loss, this issue really attracted the attention of leaders. Studies have shown that leadership support and job support are important interpersonal variables that reduce the turnover rate. Leadership concerns and support will help reduce the turnover rate of nurses [18].

\section{Summary}

1) This study clarifies the cost components of nurses' voluntary turnover. Based on the concept of literature research, theoretical review and management accounting cost, this paper puts forward that the voluntary turnover cost of nurses is divided into explicit cost and hidden cost. The explicit cost includes replacement cost, training cost, and the turnover management fee. The hidden cost includes the human capital investment costs, vacancy costs, the efficiency costs and learning curve loss costs.

2) Through the analysis of the three methods of turnover cost measurement, a similar conclusion is obtained through the practice investigation and the mathematical model: the explicit cost is about $15 \%-20 \%$ of the total cost, and the hidden cost is about the total cost $80 \%-85 \%$. Due to the short duration of the 
new staff, the trial period will be higher than the normal turnover rate of staff. So by the adjustment multiplier, you can get a more accurate voluntary turnover costs.

3) Through the empirical analysis of the voluntary turnover cost of a hospital nurse, we can further determine the calculation method of the voluntary turnover cost of nurses. At the same time, you can see the explicit cost takes up only $15 \%-20 \%$ of the total turnover costs, while the hidden costs accounted for $80 \%$ - $85 \%$ of the total turnover costs. It also needs to cause the concern of medical organizations and managers. Although the turnover cost of nurses is sometimes not high in the accounting accounts, it is only because the explicit costs are not high. In fact, the potential losses are not reflected in the financial system. So the nurses' voluntarily turnover costs are more than the manager's estimates, which should lead to sufficient attention to the leaders.

4) According to the current research, the future researches can carry out from the two aspects: first, seek new measurement methods of the turnover costs to make the turnover costs more objective and accurate. Now, the main methods are the direct estimate method and the model estimation method. These methods can calculate the approximate value of the turnover costs. Hope that future researches make up for the deficiency. Second, find ways to reduce the turnover rate. Pointing out the problem is to solve the problem. The article points out the question of the nurses' high turnover costs, but does not point out how to solve this problem. The future researches should solve the problem.

\section{References}

[1] Cao, J. and Shi, Y.P. (2013) The Reasons for Leaving and Re-Employment Intentions among Nurses in a Tertiary First-Class Hospital in Beijing. Chinese Journal of Nursing, 48, 618-620.

[2] Liu, Z.T. and Liu, G.Z. (2015) Study on Hospital Cost Control and Nursing Staff Turnover. Journal of Fuzhou University (Philosophy and Social Sciences), 126, 47-53. https://doi.org/10.1631/jzus.A1300408

[3] Hayes, L. and O’Brien-Pallas, L. (2012) Nurse Turnover: A Literature Review-An update. International Journal of Nursing Studies, 49, 887-890. https://doi.org/10.1016/j.ijnurstu.2011.10.001

[4] Song, W.C. (2016) Discussions on Human Resources Cost Accounting. Accounting and Finance, 162, 38-43.

[5] Li, Y.R. (2006) Talking about the Cost of Human Resources. Journal of Railway Engineering Society, 94, 105-107.

[6] Tang, F.P. and Mao, J.Q. (2012) Game Analysis of Job-Hopping Behavior and Organizational Control of Enterprise Trained Employees. Enterprise Economy, 38, 59-62.

[7] Smith, H.L. and Watkins, L.E. (1978) Managing Manpower Turnover Costs. The Personnel Administrator, 23, 46-50.

[8] Cascio, W.F. (1982) Costing Human Resources: The Financial Impact of Behavior in Organizations. PWS-Kent Publishing Company, Boston.

[9] Fitz-Enz, J. (1997) It's Costly to Lose Good Employees. Workforce, 76, 50-51.

[10] Pinkowitz, W.H., Moskal, J. and Green, G. (1997) How Much Does Your Employee 
Turnover Cost? Small Business Forum, 14, 70-71.

[11] Lu, Z.P. (2017) Turnover Cost and Firm-Sponsored Training. Economic Theory and Business Management, 2, 88-97.

[12] Xiong, Y.Q. and Yang, L. (2005) Discussion on Employee Mobile Cost Structure and Measurement Model. Seeking, 6, 99-101.

[13] Jones, C.B. (2004) The Costs of Nurse Turnover. Journal of Nursing Administration, 34, 562-570. https://doi.org/10.1097/00005110-200412000-00006

[14] Jones, C.B. (1990) Staff Nurse Turnover Costs. Journal of Nursing Administration, 20, 19-32. https://doi.org/10.1097/00005110-199004000-00005

[15] Jones, C.B. (1992) Calculating and Updating Nursing Turnover Costs. Nursing Economic, 10, 39-45.

[16] Jones. C.B. (2008) Revisiting Nurse Turnover Costs. Journal of Nursing Administration, 38, 11-18. https://doi.org/10.1097/01.NNA.0000295636.03216.6f

[17] Zhang, H.F. and Liu, Y.H. (2015) The Influence Factors of Nurses' Turnover Tendency. Chinese Journal of Nursing, 50, 155-160.

[18] Zhang, H.Q. (2011) Study on Human Resource Cost of Enterprise Based on AHP Method. Communication of Finance and Accounting, 23, 128-129.

Submit or recommend next manuscript to SCIRP and we will provide best service for you:

Accepting pre-submission inquiries through Email, Facebook, LinkedIn, Twitter, etc. A wide selection of journals (inclusive of 9 subjects, more than 200 journals)

Providing 24-hour high-quality service

User-friendly online submission system

Fair and swift peer-review system

Efficient typesetting and proofreading procedure

Display of the result of downloads and visits, as well as the number of cited articles

Maximum dissemination of your research work

Submit your manuscript at: http://papersubmission.scirp.org/

Or contact me@scirp.org 